\title{
Colgajo ahdominal de patrón vertical para cobertura en miembro superior. Una opción vigente y versátil en nuestro medio
}

\section{Vertical pattern abdominal flap for coverage in upper limb defects. A current and versatile option in our working environment}

\author{
María Camila JARAMILLO HURTADO*, David ZAPATA CÓRDOBA* \\ Emilio AUN DAU**, Erick AUN AUN***
}

\section{Resumen}

Introducción y objetivo. Los defectos de cobertura en la extremidad superior implican alteraciones estéticas y funcionales importantes. Como primera opción son tratados mediante microcirugía, sin embargo, en las instituciones con recursos económicos insuficientes, o en las que no está disponible este servicio, como en el Hospital San Jorge de Pereira (Colombia), los colgajos a distancia cobran gran utilidad. En la actualidad, y en nuestro medio, el colgajo abdominal de patrón vertical es nuestra primera opción para la cobertura de estos defectos.

Material y método. Estudio retrospectivo de casos atendidos en el Hospital Universitario San Jorge de Pereira (Colombia) entre 2016 y 2020, en los que se realizó cobertura de áreas cruentas en miembro superior mediante colgajo abdominal de patrón vertical.

Resultados. Recogimos un total de 10 colgajos, todos en varones, con una media de edad de 33.3 años. La etiología de los defectos fue quemadura eléctrica en 7 casos, accidente de tránsito en 2 y trauma cortocontundente en 1. En 9 pacientes el colgajo fue de base superior y en 1 caso de base inferior, todos bajo anestesia general con un tiempo quirúrgico de entre 90 y 120 minutos. La cobertura fue adecuada en el $100 \%$ de los casos, con una dehiscencia de sutura en zona receptora como única complicación.

Conclusiones. El colgajo abdominal de patrón vertical es una opción versátil, reproducible y segura, que cobra utilidad ante la ausencia de recursos o la posibilidad de realizar microcirugía. Actualmente es nuestra primera opción en cobertura de defectos en miembro superior, permitiendo obtener resultados satisfactorios con baja tasa de complicaciones.

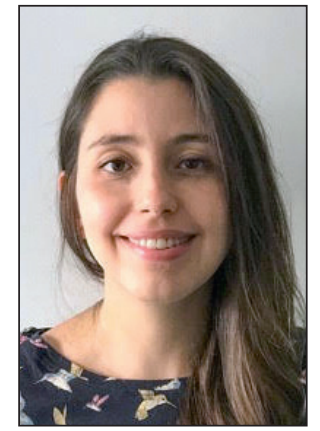

Jaramillo Hurtado M.C.

$\begin{array}{lr}\text { Palahras clave } & \begin{array}{l}\text { Colgajo abdominal, Colgajo pediculado, } \\ \text { Miembro superior, Mano, Antebrazo. }\end{array} \\ \text { Nivel de evidencia científica } & 4 c \text { Terapéutico } \\ \text { Recibido [esta versión] } & 29 \text { agosto/2020 } \\ \text { Aceptado } & 23 \text { noviembre/2020 }\end{array}$

Background and objective. Coverage defects in the upper limb have significant aesthetic and functional implications. Mostly this defects are treated by microsurgery, however in some institutions with limited economical resources or unavailability of this area, distant flaps become an important option for reconstruction. The vertical pattern abdominal flap is our first choice for the coverage of these defects.

Methods. Retrospective study of cases with upper limb coverage defects treated with vertical pattern abdominal flap at the San Jorge de Pereira Hospital (Colombia) between 2016 and 2020.

Results. Ten vertical pattern abdominal flaps were performed, all in male patients, with a mean age of 33.3 years. The etiology of the defects was electrical burn in 7 cases, traffic accident in 2 and blunt trauma in 1 . In 9 patients an upper base flap was performed and in 1 a lower base flap, all of them under general anesthesia with a surgical time between 90 and 120 minutes. Adequate coverage was obtained in $100 \%$ of the cases, with suture dehiscence in flap area as the only complication.

Conclusions. Vertical pattern abdominal flap is a versatile, reproducible, and safe option, useful in absence of resources or the possibility of performing microsurgery, Currently, it is our first option in upper limb covering defects, allowing to obtain satisfactory results with low complication rate.

Conflicto de intereses: Los autores declaran no tener ningún interés financiero relacionado con el contenido de este artículo.

Financiación: No hubo fuentes externas de financiación para este trabajo. 
Los defectos de cobertura en la extremidad superior son especialmente desafiantes ya que frecuentemente se asocian a exposición de estructuras vitales como tendones, vasos sanguíneos, nervios y hueso, lo cual demanda un oportuno abordaje y una cobertura estable dado el compromiso funcional que pueden implicar. ${ }^{(1)}$

Dentro de las opciones reconstructivas que existen para estos defectos tenemos los colgajos locales, regionales, a distancia y los colgajos libres. ${ }^{(2)}$ Los más usados en la actualidad son los colgajos libres, ${ }^{(1)} \sin$ embargo en nuestro país, Colombia, y en muchos otros países en vías de desarrollo, la mayoría de centros asistenciales no cuentan con los recursos físicos y económicos, ni con el personal debidamente entrenado para su adecuada realización. Este es el caso del Hospital Universitario San Jorge de Pereira, Colombia, el cual es una entidad del estado de nivel III de complejidad que cuenta con Servicio de Cirugía Plástica general, sin área de Microcirugía.

Según lo anteriormente mencionado, los colgajos a distancia siguen siendo una opción vigente, que en nuestro medio, brinda un adecuado abordaje reconstructivo a este tipo de patología. ${ }^{(1)}$

El colgajo abdominal de patrón vertical es un colgajo pediculado aleatorizado que puede ser disecado con base superior o inferior dadas las características vasculares propias de esta área anatómica. ${ }^{(3,4)}$ Es un colgajo versátil que permite la cobertura adecuada de defectos significativos en diversas áreas del miembro superior, como el antebrazo, la mano y los dedos. Se trata de un colgajo de composición dermograsa, de patrón aleatorio, cuya vascularización proviene del plexo subdérmico. ${ }^{(2)}$ Se puede orientar para su elevación de acuerdo a la localización anatómica del defecto a tratar, ya sea con una base superior manteniendo un flujo anterógrado o con una base inferior con un flujo retrógrado.

Las características de la pared abdominal, la piel y el tejido celular subcutáneo, hacen posible la elevación de colgajos de esta zona con un tamaño suficiente para cubrir áreas de dimensiones variables, manteniendo la relación 3:1. Esto permite la cobertura tanto de defectos pequeños de los dedos, como de grandes defectos del antebrazo y la mano, en su cara volar y dorsal.

Presentamos 10 casos realizados en el Hospital San Jorge de Pereira, en Colombia, de reconstrucción de defectos de cobertura en miembro superior mediante colgajo abdominal de patrón vertical. Dada la versatilidad de este colgajo, esperamos sea de gran utilidad en instituciones con bajos recursos o que no cuentan con Servicio de Microcirugía para este fin, como es nuestro caso.
Realizamos un análisis retrospectivo de los pacientes a los que se les efectuó un colgajo abdominal de patrón vertical para cobertura de defectos en miembro superior, atendidos en el Hospital Universitario San Jorge de Pereira (Colombia) entre 2016 y 2020. Incluimos en el estudio pacientes con defectos de cobertura en pliegue antecubital del codo, antebrazo y mano, con exposición de estructuras vitales y en los cuales un colgajo regional no logrará abarcar el área suficiente para la cobertura completa de los mismos. Excluimos aquellos pacientes con infecciones activas, defectos en hombro y brazo o con defectos de cobertura sin exposición de estructuras vitales.

Como protocolo prequirúrgico, evaluamos el perfil nutricional así como la pared abdominal de los pacientes en busca de cicatrices quirúrgicas, hernias u otras patologías que pudieran contraindicar el colgajo o que requirieran una reparación concomitante al procedimiento, con el fin de llevar al paciente en optimas condiciones a la realización del colgajo.

Recopilamos los datos clínicos para el estudio de las historias clínicas de los pacientes previa autorización de los mismos y del Comité Estadístico de la institución. Tomamos en cuenta variables como la edad, el sexo, la etiología de la lesión, el área afectada, la extensión de la lesión, procedimientos quirúrgicos complementarios, tipo de anestesia utilizada, tiempo quirúrgico y complicaciones. Analizamos estos datos mediante el uso de estadística descriptiva y los presentamos en forma de variables absolutas y relativas.

\section{Técnica quirúrgica}

Todos los pacientes fueron operados bajo anestesia general, previa firma de consentimiento informado. La orientación de la base del pedículo del colgajo se estableció en cada caso según la localización del defecto a tratar y la facilidad de anclaje del colgajo al lecho receptor. Realizamos técnica de pellizco digital (pinch test) en la piel abdominal como parámetro principal para la marcación; esto permitió definir el ancho de la base del colgajo adecuado para lograr el cierre primario de cada una de las áreas donantes.

Establecimos como límites para la disección del colgajo superior $2 \mathrm{~cm}$ por debajo del reborde costal, medial a $2 \mathrm{~cm}$ de la línea alba, e inferior hasta la cresta iliaca y la sínfisis púbica, sin sobrepasar en ningún caso estas estructuras (Fig. 1). Al tratarse de un colgajo aleatorio basado en el plexo subdérmico, no fue necesario el uso de doopler para su planificación.

Iniciamos la incisión y elevación del colgajo en todos los casos de distal hacia proximal, en un plano suprafas- 


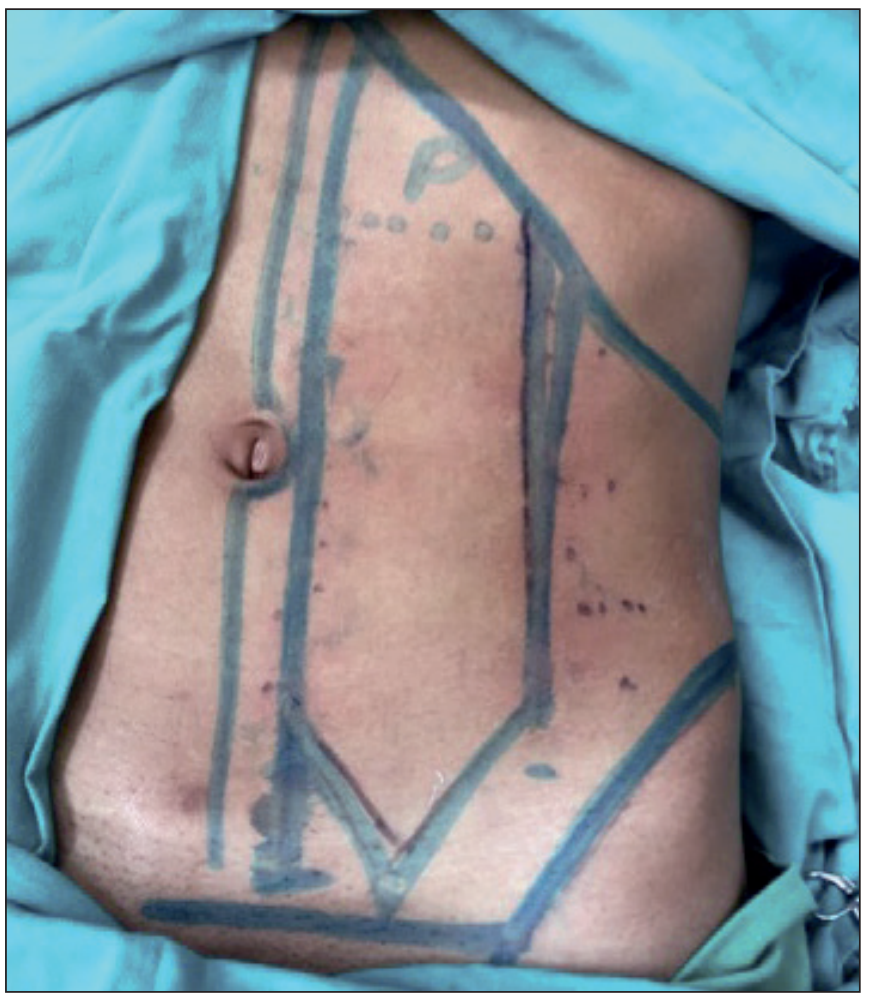

Figura 1. Marcaje preoperatorio del colgajo abdominal con anchura de 7-10 cm y longitud de 21-30 cm, respetando relación 3:1. Límite superior a $2 \mathrm{~cm}$ por debajo del reborde costal, medial a $2 \mathrm{~cm}$ de la línea alba e inferior hasta la cresta ilíaca y la sínfisis púbica, sin sobrepasar estas estructuras. cial muscular (Fig. 2C, 4B, 5C). Colocamos puntos de sutura absorbible anclando la cara profunda del colgajo a la dermis, disminuyendo así el posible cizallamiento y la lesión de los vasos provenientes de las fascias de Camper y Scarpa. En el área donante realizamos cierre primario por planos y en el área receptora fijamos el colgajo con sutura absorbible en los sitios de mayor tensión y con sutura no absorbible en las áreas libres de tensión (Fig. 2D, 3C). En ningún caso fue necesaria la colocación de drenajes. Al finalizar el procedimiento, envolvimos el colgajo en gasas parafinadas dejando una ventana para su seguimiento. Colocamos también puntos antitracción con seda en la piel sana del antebrazo y de la mano, que anclamos a la piel sana del abdomen (Fig. 6B). Finalmente protegemos los pliegues axilares con apósitos locales.

El segundo tiempo quirúrgico fue la liberación del colgajo, que llevamos a cabo igualmente bajo anestesia general y de forma ambulatoria, tras un periodo de tiempo no menor a 25 días y no mayor a 30 días a partir de la primera intervención (Fig. 3 A-C, 6D, E, y 7B).

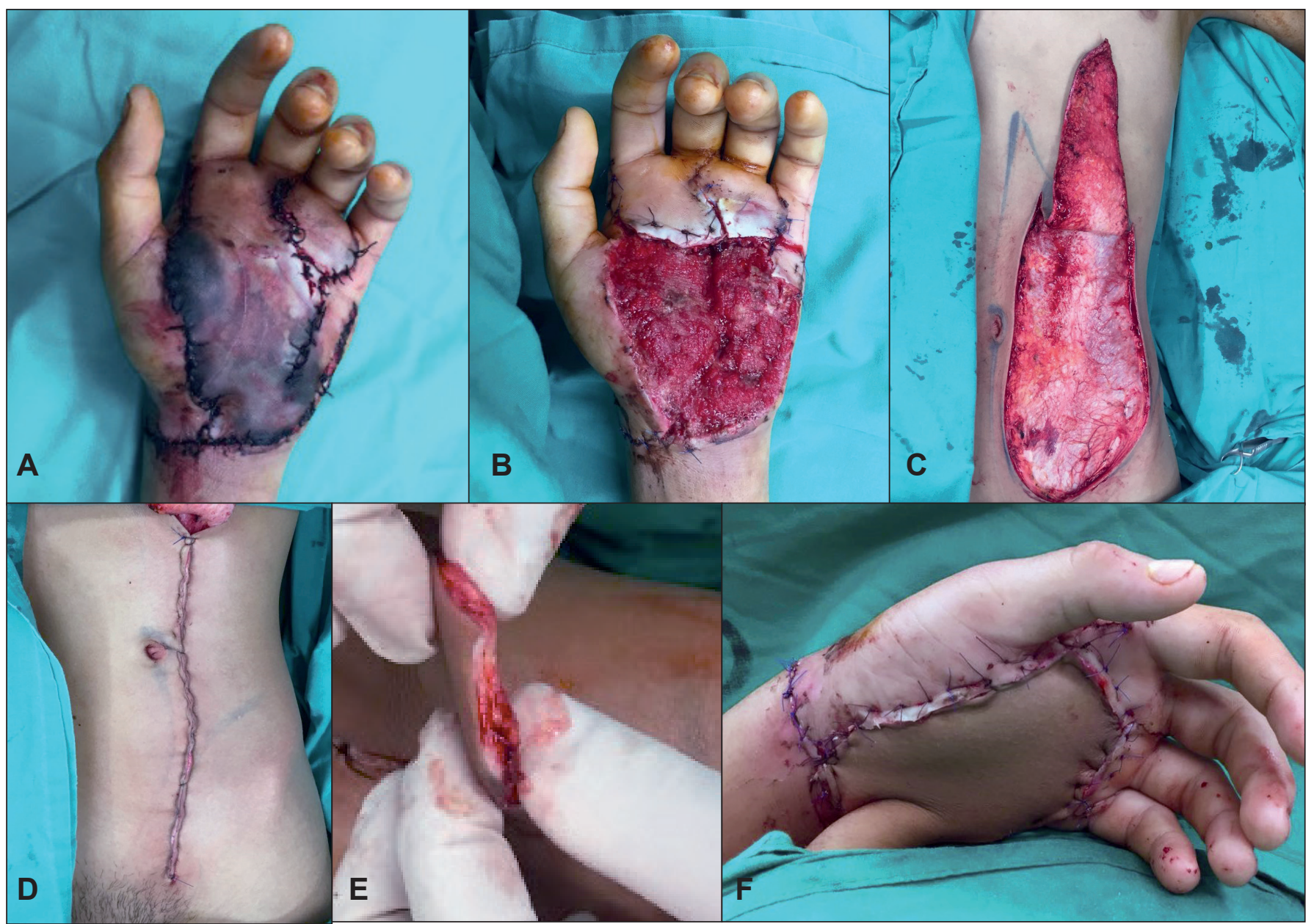

Figura 2. Varón de 23 años con defecto de cobertura en palma izquierda secundario a quemadura eléctrica. Primer tiempo quirúrgico: A. Región palmar con piel necrótica. B. Defecto de cobertura de $10 \times 9 \mathrm{~cm}$ de diámetro con exposición de estructuras tendinosas. C. Levantamiento de colgajo abdominal a nivel suprafascial muscular. D. Cierre primario del área donante en la pared abdominal. E. Grosor del colgajo $1.2 \mathrm{~cm}$. F. Fijación del colgajo al área receptora, logrando cubrir todas las estructuras vitales expuestas. 


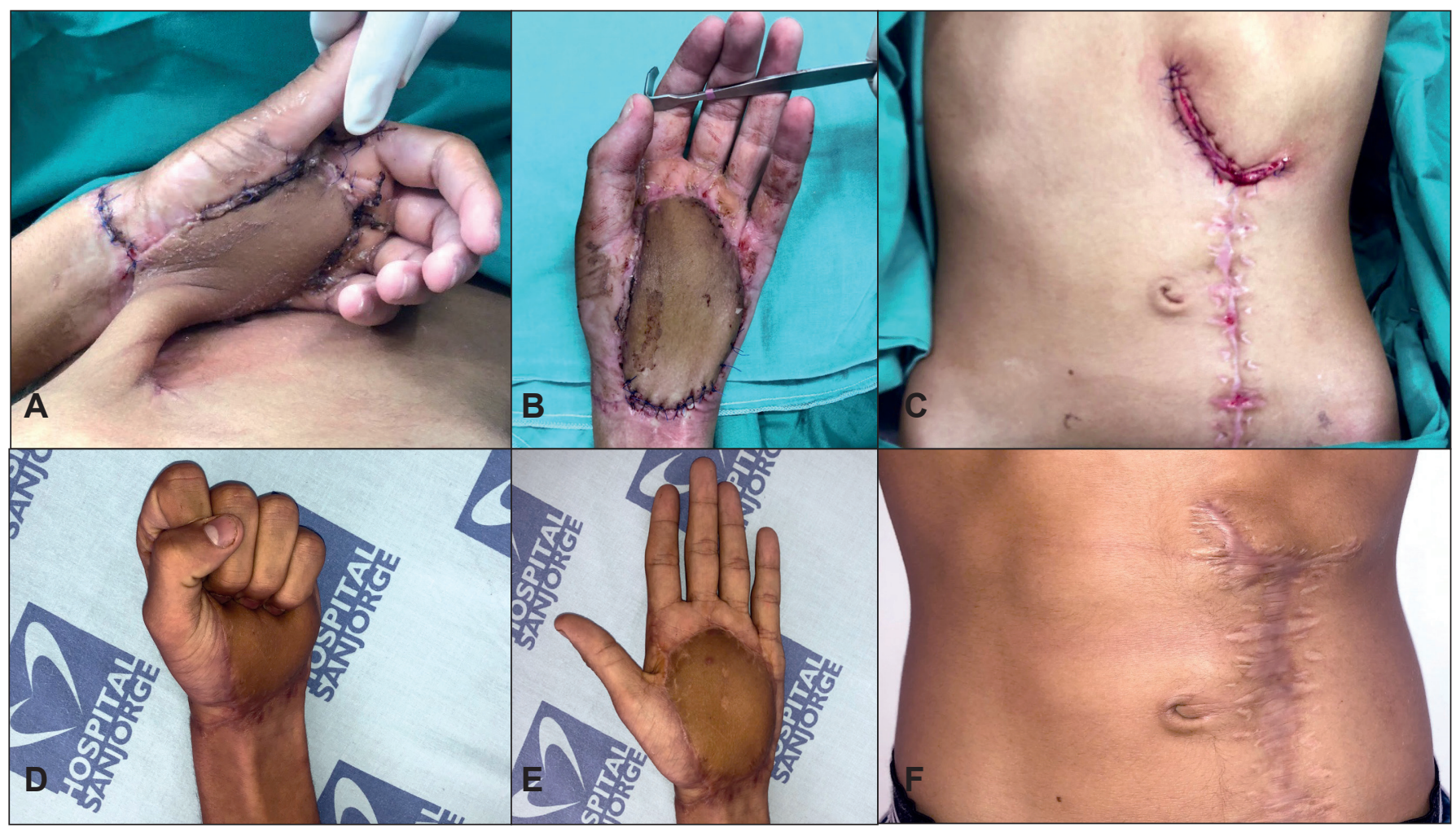

Figura 3. Varón de 23 años con defecto de cobertura en palma izquierda de $10 \times 9 \mathrm{~cm}$ secundario a quemadura eléctrica A. Segundo tiempo quirúrgico antes de la liberación del colgajo. B: Segundo tiempo quirúrgico, colgajo abdominal liberado. C. Segundo tiempo quirúrgico, cicatriz del cierre primario del área donante en la pared abdominal. D-E. Control posoperatorio a los 6 meses: colgajo vital con grosor adecuado, flexión y extensión completa de los dedos. F, Control posoperatorio a los 6 meses: cicatriz en área donante en la pared abdominal en proceso de maduración.

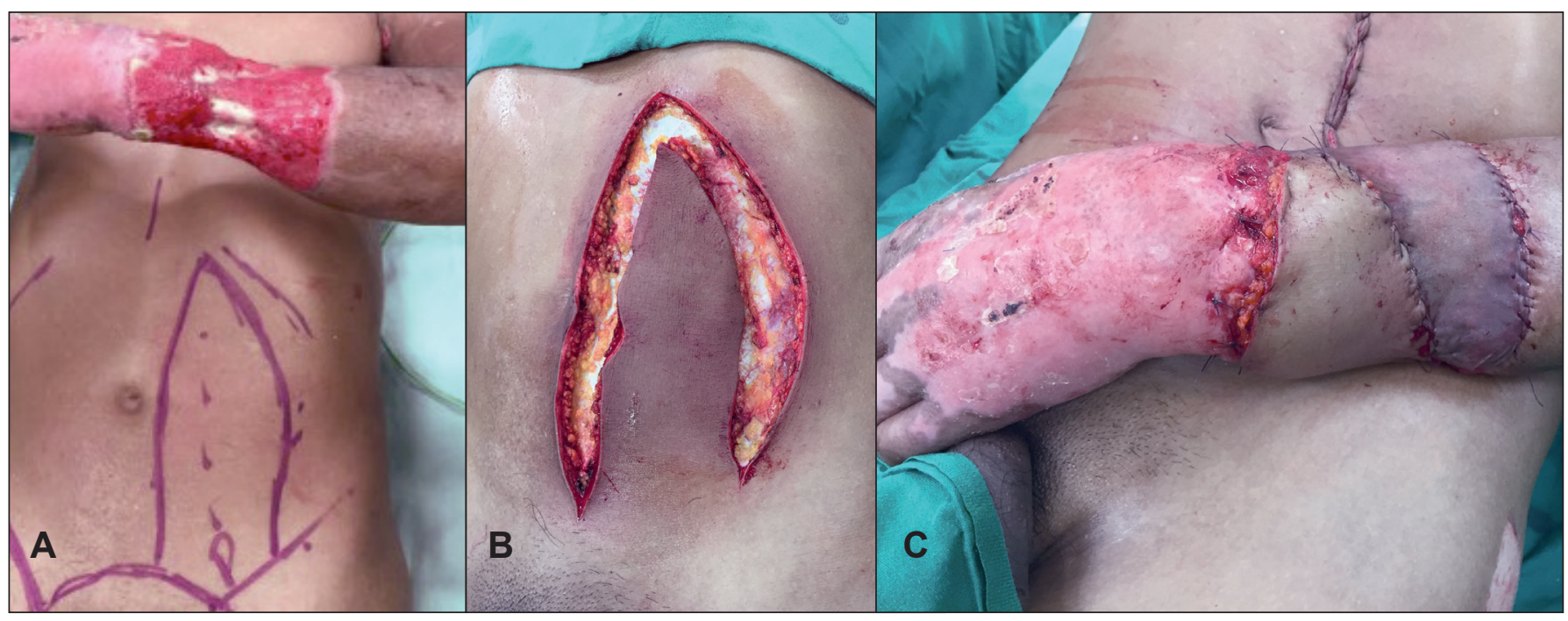

Figura 4. Varón de 24 años con defecto de cobertura en cara dorsal de tercio distal de antebrazo izquierdo secundario a quemadura eléctrica. Primer tiempo quirúrgico: A. Defecto de cobertura de $12 \times 8 \mathrm{~cm}$ de diámetro con exposición ósea; marcaje del colgajo abdominal de base inferior con flujo retrógrado. B. Levantamiento del colgajo a nivel suprafascial muscular. C. Fijación del colgajo al área receptora logrando cubrir todas las estructuras vitales expuestas; colocación de injerto de piel parcial para cubertura del tejido de granulación.

\section{Manejo posoperatorio}

Con relación al primer tiempo quirúrgico, el primer día del posoperatorio, con el paciente en decúbito supino, colocamos férula de yeso de 10 vueltas abrazando el tórax y el brazo del paciente, distante al colgajo para no interferir con la vigilancia del mismo y las curas periódicas (Fig. 8).

La estancia posquirúrgica fue de 3 a 5 días con egreso hospitalario una vez realizado el primer cambio de apósitos. El seguimiento fue ambulatorio, con curas en clínica de heridas cada quinto día y un protocolo individualizado de terapia física en casa instaurado por el Servicio de Fisioterapia y Rehabilitación y sujeto a las condiciones y lesiones propias de cada paciente.

Con relación al segundo tiempo, realizamos curas cada quinto día en la clínica de heridas, con retirada de puntos de sutura a los 15 días de la intervención. Los pacientes siguieron un plan individualizado de rehabilitación, con seguimiento hasta los 6 meses de posoperatorio en todos los casos (Fig. 3D, E y 6E). 


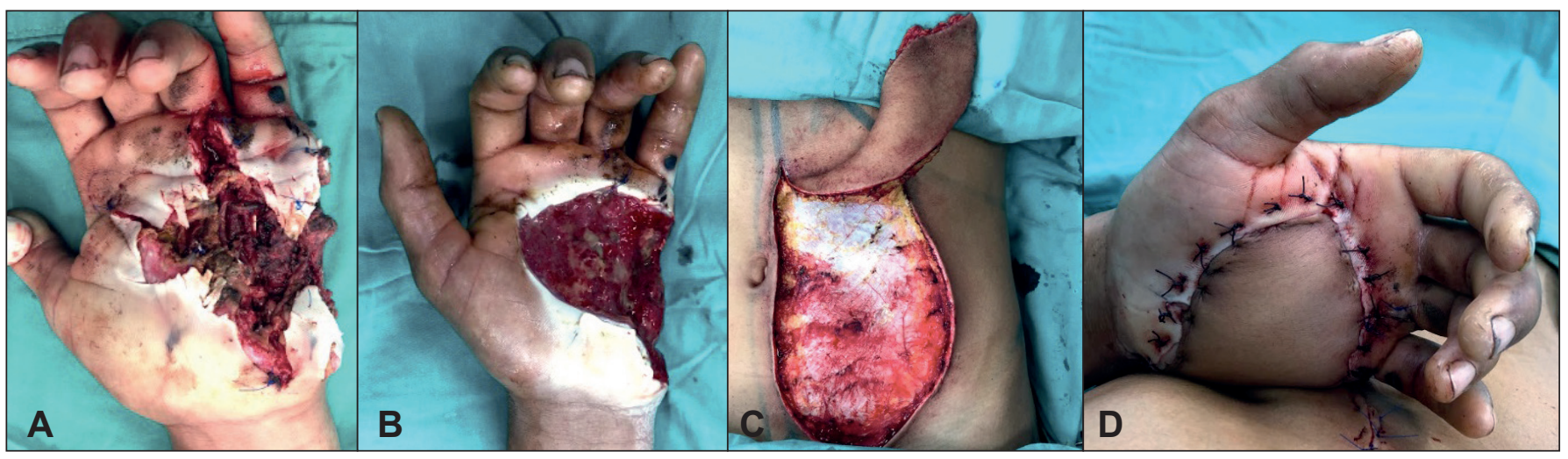

Figura 5. Varón de 27 años con defecto de cobertura en región palmar izquierda secundario a accidente de tránsito. A. Herida traumática con tejido necrótico y exposición de estructuras vitales. B. Defecto de cobertura resultante en región palmar de $8 \times 6 \mathrm{~cm}$ de diámetro, con exposición de estructuras vitales. C-D. Primer tiempo quirúrgico: levantamiento del colgajo abdominal de base superior y colocación sobre el área receptora, logrando cubrir todas las estructuras vitales expuestas.

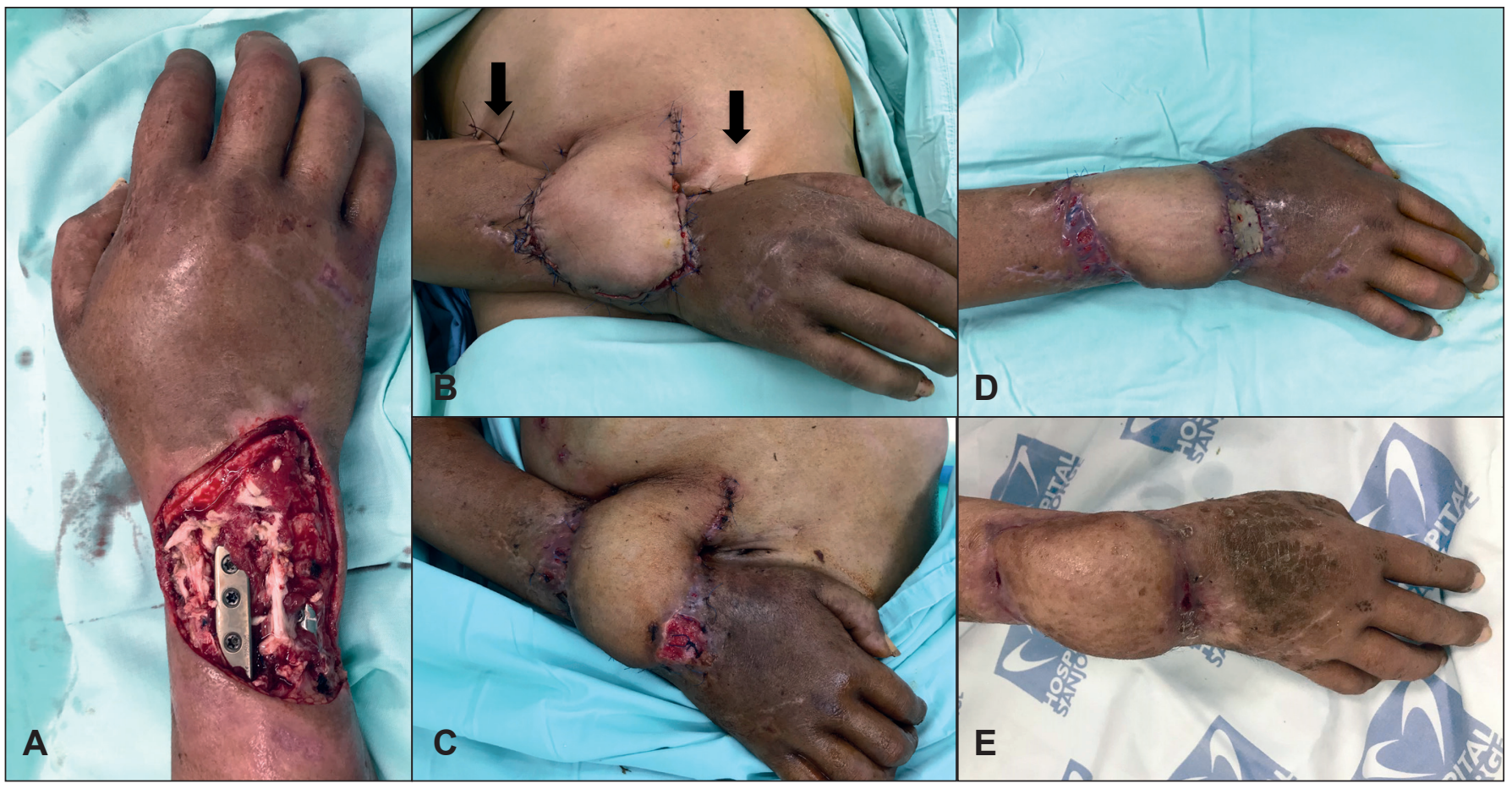

Figura 6. Varón de 47 años con defecto de cobertura en cara dorsal de tercio distal de antebrazo derecho secundario a trauma cortocontundente. A. Defecto de cobertura de $12 \times 9 \mathrm{~cm}$ de diámetro con exposición de material de osteosíntesis y estructuras tendinosas. B. Primer tiempo quirúrgico: fijación del colgajo al área receptora logrando cubrir todas las estructuras vitales expuestas, colocación de sutura antitracción. C. Área de dehiscencia a las 5 horas de $2 \times 2 \mathrm{~cm}$, con tejido de granulación. D. Segundo tiempo quirúrgico: colgajo liberado, injerto de piel total en área de dehiscencia. E. Control posoperatorio a los 6 meses.

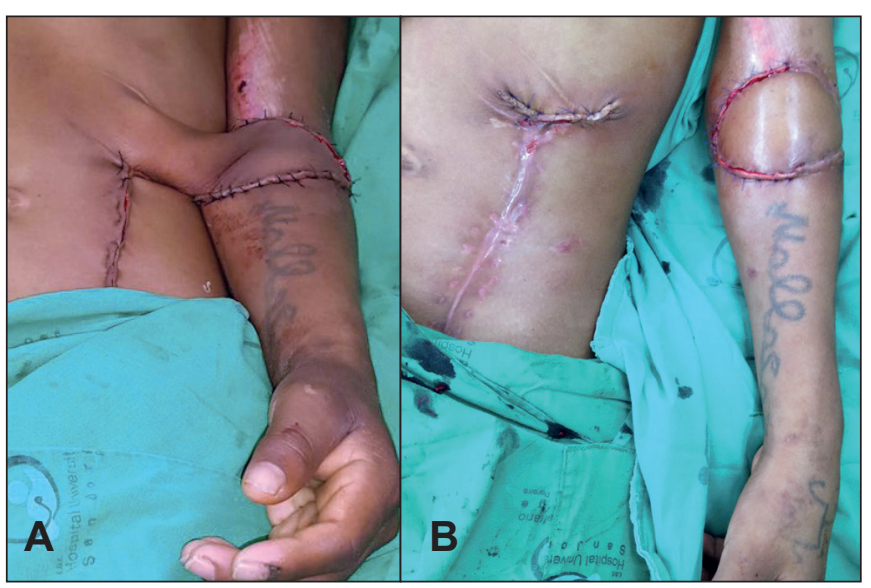

Figura 7. Varón de 34 años con defecto de cobertura de $8 \times 6 \mathrm{~cm}$ de diámetro en fosa antecubital izquierda secundario a quemadura eléctrica, cubierto con colgajo abdominal de base superior. A. Primer tiempo quirúrgico: colgajo abdominal fijado al área receptora logrando cubrir todas las estructuras vitales expuestas. B. Segundo tiempo quirúrgico: colgajo abdominal liberado de su pedículo.

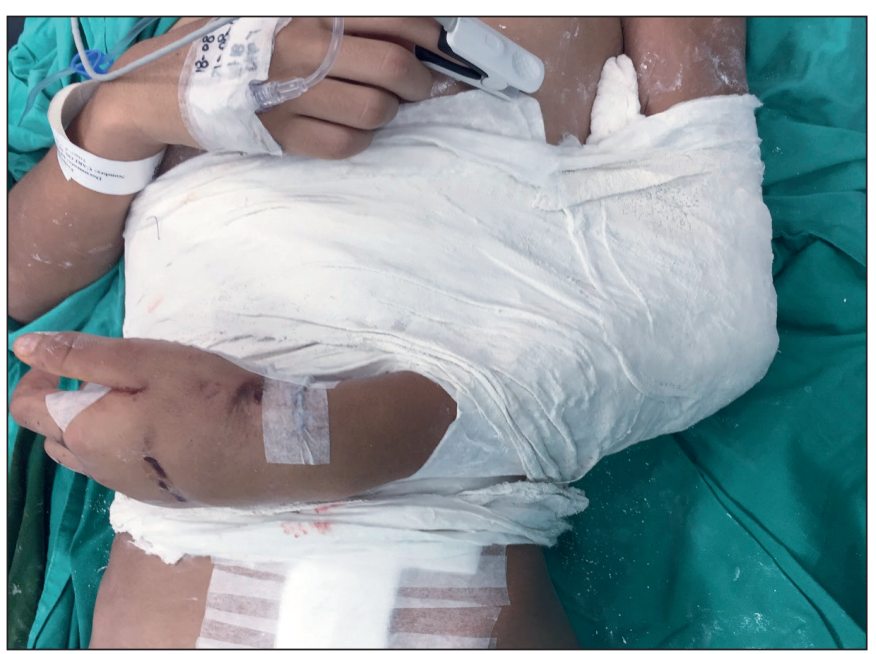

Figura 8. Inmovilización del miembro superior mediante colocación de férula de yeso de 10 vueltas abrazando el tórax y el brazo del paciente, colocada distante al colgajo, para no interferir con la vigilancia del mismo y las curas periódicas. 
Resultados

Estudiamos un total de 10 pacientes con un rango de edad entre los 23 a 52 años (media de 33.3 años), todos de sexo masculino (Tabla I). La etiología de los defectos fue en 7 casos secundaria a quemadura eléctrica de alto voltaje (70\%), en 2 casos por accidente de tránsito $(20 \%)$ y en 1 caso por trauma cortocontundente $(10 \%)$. La localización de los defectos fue 4 casos en cara volar del tercio distal del antebrazo (40\%), 1 caso en cara volar tercio proximal del antebrazo a nivel de la fosa antecubital $(10 \%), 1$ caso en cara dorsal de tercio distal del antebrazo $(10 \%), 2$ en cara dorsal de tercio medio del antebrazo $(20 \%)$ y 2 en región palmar (20\%). El diámetro de los defectos osciló entre 6 a $12 \mathrm{~cm}$ de longitud (media de $8.7 \mathrm{~cm}$ ) y 5 a $9 \mathrm{~cm}$ de anchura (media de $7.4 \mathrm{~cm}$ ) (Tabla II).

En 9 casos el colgajo abdominal fue de patrón vertical de base superior (90\%) ipsilateral al defecto de cobertura $\mathrm{y}$ en 1 caso de base inferior (10\%) igualmente ipsilateral al defecto. La longitud de los colgajos osciló entre los 21 a $30 \mathrm{~cm}$ (media de $24.3 \mathrm{~cm}$ ) y la anchura de entre 7 a 10 $\mathrm{cm}$ (media de $8.8 \mathrm{~cm}$ ), respetando siempre la relación 3:1 (Fig. 1). Cabe hacer notar que en 8 de 10 casos, en cuanto a la longitud del colgajo, no fue necesario triplicar el ancho, pues un colgajo de menor longitud fue suficiente para lograr la cobertura adecuada de los defectos, lo que proporcionó al colgajo mayor seguridad en cuanto a su irrigación.

Tabla 1: Características de los pacientes

\begin{tabular}{|l|l|l|}
\hline VARIABLE & $\mathbf{n}$ & $\%$ \\
\hline Sexo & $\mathbf{n}$ & $\%$ \\
Masculino & 10 & 100 \\
\hline Total & $\mathbf{1 0}$ & $\mathbf{1 0 0}$ \\
\hline VARIABLE & $\mathbf{n}$ & $\%$ \\
\hline Edad & $\mathbf{n}$ & $\%$ \\
De 20-30 años & 4 & 40 \\
De $30-40$ años & 4 & 40 \\
De 40-50 años & 1 & 10 \\
De 50-60 años & 1 & 10 \\
\hline Total & $\mathbf{1 0}$ & $\mathbf{1 0 0}$ \\
\hline
\end{tabular}

Tabla 2: Características del defecto de cobertura

\begin{tabular}{|l|l|l|}
\hline VARIABLE & $\mathbf{n}$ & $\%$ \\
\hline Etlología & & \\
Quemadura eléctrica & 7 & 70 \\
Trauma cortocontundente & 1 & 10 \\
Accidente de transito & 2 & 20 \\
\hline Total & 10 & 100 \\
\hline VARIABLE & $\mathbf{n}$ & $\%$ \\
\hline SItlo del defecto & & \\
Cara volar antebrazo tercio distal & 4 & 40 \\
Cara volar antebrazo tercio proximal & 1 & 10 \\
Cara dorsal antebrazo tercio distal & 1 & 10 \\
Cara dorsal antebrazo tercio medio & 2 & 20 \\
Palma de la mano & 2 & 20 \\
\hline Total & 10 & 100 \\
\hline VARIABLE & $\mathbf{n}$ & $\%$ \\
\hline Longitud del defecto (cm) & & \\
6-B & 6 & 60 \\
9-11 & 2 & 20 \\
12 & 2 & 20 \\
\hline Total & 10 & 10200 \\
\hline VARIABLE & $\mathbf{n}$ & $\%$ \\
\hline Anchura del defecto (cm) & & \\
5-6 & 4 & 40 \\
7-8 & 3 & 30 \\
9 & 3 & 30 \\
\hline Total & 10 & 100 \\
\hline & & \\
\hline
\end{tabular}

Todos los casos se realizaron bajo anestesia general en un rango de tiempo operatorio de entre 90 y $120 \mathrm{mi}-$ nutos (media de 100 minutos) (Tabla III).

El colgajo tuvo una supervivencia del $100 \%$ en todos los casos y como única complicación se presentó una dehiscencia menor de $2 \mathrm{~cm}$ en el área receptora en 1 paciente (10\%), que manejamos mediante curas e injerto en el momento de la liberación del colgajo, obteniendo una adecuada cobertura, sin áreas cruentas residuales (Tabla III).

Todos los pacientes toleraron adecuadamente el procedimiento.

Además de la cobertura, todos los casos requirieron procedimientos complementarios según la lesión especifica. En los casos de quemadura eléctrica, 6 de los 7 pacientes fueron llevados a fasciotomía descompresiva de miembro superior en la fase aguda de la quemadura $(60 \%)$. El caso restante presentó delimitación de la lesión en el pliegue antecubital, exponiendo el nervio mediano y la arteria braquial, pero sin llegar a comprometerla, por lo cual no requirió fasciotomia (Fig. 7). Los 7 pacientes requirieron desbridamiento hasta tejido sano (70\%) (Tabla IV).

Tabla 3: Características de la intervención quirúrgica

\begin{tabular}{|c|c|c|}
\hline VARIABLE & $n$ & $\%$ \\
\hline $\begin{array}{l}\text { Tipo de colgajo } \\
\text { Colgajo de base superior } \\
\text { Colgaio de base inferior }\end{array}$ & $\begin{array}{l}9 \\
1\end{array}$ & $\begin{array}{l}90 \\
10\end{array}$ \\
\hline Total & 10 & 100 \\
\hline VARIABLE & $n$ & $\%$ \\
\hline $\begin{array}{l}\text { Longitud del colgajo } \\
\text { (cm) } 21-23 \\
24-26 \\
27-29 \\
30\end{array}$ & $\begin{array}{l}6 \\
1 \\
2 \\
1\end{array}$ & $\begin{array}{l}60 \\
10 \\
20 \\
10\end{array}$ \\
\hline Total & 10 & 100 \\
\hline VARIABLE & $n$ & $\%$ \\
\hline $\begin{array}{l}\text { Anchura del colgalo }(\mathrm{cm}) \\
7-8 \\
9-10\end{array}$ & $\begin{array}{l}4 \\
6\end{array}$ & $\begin{array}{l}40 \\
60\end{array}$ \\
\hline Total & 10 & 100 \\
\hline VARIABLE & $n$ & $\%$ \\
\hline $\begin{array}{l}\text { Tlempo quirúrglco } \\
90-120 \text { minutos }\end{array}$ & 10 & 100 \\
\hline Total & 10 & 100 \\
\hline VARIABLE & $n$ & $\%$ \\
\hline $\begin{array}{l}\text { Anestesla } \\
\text { General }\end{array}$ & 10 & 100 \\
\hline Total & 10 & 100 \\
\hline VARIABLE & $n$ & $\%$ \\
\hline $\begin{array}{l}\text { Evoluclón del colgajo } \\
\text { Supervivencia }\end{array}$ & 10 & 100 \\
\hline Total & 10 & 100 \\
\hline VARIABLE & $n$ & $\%$ \\
\hline $\begin{array}{l}\text { Complicaciones área receptora } \\
\text { Dehiscencia }<2 \mathrm{~cm}\end{array}$ & 1 & 10 \\
\hline Total & 10 & 100 \\
\hline VARIABLE & $n$ & $\%$ \\
\hline $\begin{array}{l}\text { Complicaciones área donante } \\
\text { Ninguna }\end{array}$ & 10 & 100 \\
\hline Total & 10 & 100 \\
\hline
\end{tabular}

Tabla 4: Procedimientos quirúrgicos adicionales

\begin{tabular}{|l|l|l|}
\hline VARIABLE & $\mathbf{n}$ & $\%$ \\
\hline Procedimientos quirúrgicos adicionales & & \\
Easciotemia descompresiva & 6 & 60 \\
Desbridamiento & 10 & 100 \\
Tenorrafia & 3 & 30 \\
Neurorrafia & 3 & 30 \\
Osteosintesis & 3 & 30 \\
\hline
\end{tabular}


En lo referente a los 2 casos de trauma por accidente de tránsito, requirieron tenorrafia $(20 \%)$ y neurorrafia (20\%), así como osteosíntesis percutánea en la fase inicial $(20 \%)$. Posteriormente presentaron profundización de la quemadura por fricción en la piel y finalmente exposición de tejidos vitales, por lo cual fueron llevados a desbridamiento previo a la cobertura (20\%) (Tabla IV).

El caso restante, secundario a trauma cortocontundente relacionado con herida severa en tercio medio de antebrazo con fractura transversa asociada de radio y cubito y sección de todos los tendones extensores, nervio mediano, flexor largo de pulgar y flexor profundo del $4^{\circ}$ dedo, requirió tenorrafia $(10 \%)$ y neurorrafia $(10 \%)$ por parte de nuestro Servicio y osteosíntesis por parte de Ortopedia (10\%). A las 3 semanas de la intervención inicial, evidenciamos una dehiscencia significativa del colgajo de piel, así como necrosis parcial de tejidos blandos con exposición de estructuras vitales y de material de osteosíntesis, por lo que necesitó desbridamiento previo a la realización del colgajo (10\%) (Tabla IV).

\section{Discusión}

En nuestro estudio presentamos 10 casos tratados en el Hospital San Jorge de Pereira (Colombia), consistentes en reconstrucción de defectos de cobertura en miembro superior mediante colgajo abdominal de patrón vertical. Este colgajo, dada su versatilidad, permite la cobertura de defectos en miembro superior en instituciones con bajos recursos o que no cuentan con Servicio de Microcirugía para este fin.

Dentro de las opciones reconstructivas establecidas para el tratamiento de los defectos de cobertura en miembro superior, encontramos en primera instancia los colgajos locales y regionales. Estos presentan una corta movilidad en la extremidad superior y por su cercanía al área traumatizada, su uso se ve limitado a la cobertura de áreas cruentas pequeñas. ${ }^{(5)}$ Igualmente, generan morbilidad significativa en la zona donante. ${ }^{(6)}$

Por su parte, los colgajos microvasculares son en la actualidad el modelo a seguir en reconstrucción, ya que potencialmente permiten la reconstrucción en un solo tiempo quirúrgico, logrando una adecuada cobertura temprana, estética y funcional. ${ }^{(1,7-9)}$ También son útiles en defectos complejos donde pueden aportar otro tipo de estructuras, como tendones o hueso. ${ }^{(10,11)}$ Sin embargo, debemos tener en cuenta que estos colgajos implican procedimientos que requieren un tiempo quirúrgico prolongado, son costosos y necesitan personal especializado para su realización, características con las que no cuentan muchos de los centros asistenciales en los países en vías de desarrollo. En nuestro caso, el Hospital Universitario
San Jorge de Pereira no cuenta con Servicio de Microcirugía, por lo cual nuestra primera opción de tratamiento son los colgajos a distancia.

Dentro de las opciones reconstructivas mediante colgajos a distancia encontramos el colgajo torácico, el deltopectoral, el inguinal y el abdominal, ${ }^{(12)}$ estos dos últimos son los más frecuentemente utilizados.

El colgajo inguinal, descrito en 1972 por Mcgregor y Jackson, ${ }^{(13)}$ es un colgajo de patrón axial basado en la arteria ilíaca circunfleja superficial, que se origina de la arteria femoral, $2 \mathrm{~cm}$ por debajo del ligamento inguinal, cruza el músculo sartorio y discurre lateralmente hacia la espina ilíaca anterosuperior. Dentro de las complicaciones asociadas a este colgajo, está la pérdida de sensibilidad secundaria a lesión del nervio cutáneo femoral lateral, la cual ha sido reportada hasta en el 50\% de los casos. Igualmente, es un colgajo que al ser axial requiere disección hasta la fascia abdominal, lo que genera en muchas ocasiones que el grosor del colgajo implique un adelgazamiento posterior a su liberación. ${ }^{(1,14)}$ La pérdida de sensibilidad secundaria en un alto porcentaje de casos y la limitación en cuanto al nivel de disección de este colgajo hacen que ocupe un segundo puesto en nuestras opciones reconstructivas.

El colgajo abdominal es un colgajo, aleatorio basado en el plexo subdérmico que puede ser mono, bi o multipediculado según la necesidad del paciente. Puede ser disecado con diferentes grosores que varían desde colgajos superdelgados con una mínima porción de tejido celular subcutáneo integrado, a colgajos gruesos con disección hasta la fascia abdominal, lo que permite un resultado estéticamente apropiado e individualizado para la cobertura de áreas cruentas en el miembro superior. ${ }^{(1,8,9,12,15)}$ Las características previamente mencionadas hacen que el colgajo abdominal sea una opción versátil en cuanto a su orientación y nivel de disección, permitiendo la cobertura de múltiples defectos en miembro superior y convirtiéndose de esta manera en nuestra primera opción reconstructiva.

En nuestro estudio, aunque la disección en todos los casos se realizó hasta la fascia muscular, en ninguno fue necesario el adelgazamiento de los colgajos, ya que todos tenían un grosor aceptable desde el inicio e igualmente se contrajeron con el tiempo, lo que permitió un buen resultado estético. Solo en 1 caso se propuso la realización de adelgazamiento, sin embargo el paciente estaba satisfecho con el resultado y no aceptó una nueva intervención.

El colgajo abdominal se puede realizar de forma fiable, segura y en un corto periodo de tiempo; además permite la cobertura de grandes área, ${ }^{(12)}$ y no necesita recursos costosos para su realización. ${ }^{(1)}$ La disección de este colgajo con un patrón vertical aumenta la versatilidad del mismo, ya que su disección orientando su pedículo a 
nivel del hemiabdomen superior o inferior según la necesidad, permite lograr la cobertura de cualquier defecto en el miembro superior distal al codo. Este patrón de disección facilita también el cierre del área donante sin tensión, evitando así el uso de injertos de piel en dicha área, que sí se hacen necesarios cuando el colgajo se levanta con un patrón horizontal.

En nuestra serie de casos, los defectos afectaban a la cara volar y dorsal del alntebrazo y a la región palmar. Señalar también que adicionalmente este colgajo permite la cobertura de defectos en tórax anterior, ${ }^{(16)}$ lo cual hemos podido comprobar en 1 caso realizado igualmente en nuestra institución.

Existen algunas situaciones en las cuales se podría considerar el uso de colgajos pediculados abdominales frente a los colgajos libres. ${ }^{(7,9,17)}$ Mohammad y col., en 2016, mencionaron algunas de estas indicaciones, entre las cuales encontramos las lesiones extensas por deguantamiento, los defectos simultáneos en múltiples dígitos, los defectos complejos en mano en niños menores de 2 años, los politraumatismos, la presencia de enfermedades graves concomitantes y las quemaduras eléctricas de alto voltaje, en las cuales la mano está vital gracias a la circulación colateral.(7,8) Las quemaduras eléctricas son especialmente propensas al fracaso en reconstrucción con colgajos libres, pues en ellas aumenta el riesgo de oclusión vascular, la formación de aneurismas o la trombosis, ya que esta patología se ve frecuentemente asociada a un estado vascular precario en la extremidad. ${ }^{(18,19)}$

Señalar que, aunque la principal etiología de los defectos de cobertura que presentamos en nuestra serie de casos fue la quemadura eléctrica, la indicación del colgajo abdominal de patrón vertical en nuestro caso estuvo dada por la ausencia de Servicio de Microcirugía en nuestra institución.

Dentro de las principales desventajas a tener en cuenta en este tipo de colgajos encontramos la necesidad de 2 tiempos quirúrgicos, liberando el colgajo habitualmente a las 3 semanas de la primera intervención. ${ }^{(1)}$ También el periodo de inmovilización requerido entre ambos tiempos, el aumento relativo de la estancia hospitalaria, la incomodidad del paciente y el hecho de que puede generar cierto grado de rigidez por inmovilidad en el miembro superior. ${ }^{(1,5,7,20)}$ Nuestros pacientes aceptaron en su totalidad la necesidad de 2 tiempos quirúrgicos, y realizamos el segundo a las 4 semanas dadas las características demográficas de nuestra población, ya que Colombia es un país en donde cerca de 20 millones de personas no tienen acceso a los productos básicos de la canasta familiar, en el que el $34.1 \%$ vive en pobreza y el $10.6 \%$ prácticamente en la indigencia, ${ }^{(21)}$ razones por las cuales el riesgo de déficit nutricional que afecta directamente a la evolución de cualquier colgajo, es inminente. En cuanto al tiempo de inmovilización y el tiempo de hospitalización, en nuestros casos fue adecuadamente tolerado y con relación a la rigidez por inmovilidad, la manejamos mediante un protocolo de terapia física que permitió la recuperación adecuada de la movilidad dentro de lo esperado para la patología de cada paciente (Fig. 3 D-E).

Dentro de las complicaciones que se pueden presentar, una de las más temidas es la necrosis del colgajo, ya sea parcial o total, que en la literatura aparece en el 3.4 al $27.3 \%$ de los casos. Normalmente esta necrosis está asociada a áreas de defectos pequeños. ${ }^{(1)}$ En nuestra serie de casos no tuvimos ninguna necrosis.

Consideramos que, en nuestro medio, contamos con un colgajo versátil que nos permite la adecuada cobertura en miembro superior y aunque en algunas ocasiones es la primera opción frente a la Microcirugía, esta última es un recurso valioso e ideal en cualquier institución.

\section{Conclusiones}

El colgajo abdominal cobra utilidad en cualquier defecto de miembro superior ante la ausencia de Microcirugía y en caso de contar con recursos limitados; adicionalmente es de principal elección en casos específicos, como defectos extensos por deguantamiento o defectos simultáneos en múltiples dígitos, entre otros. Su disección con un patrón vertical es una opción versátil, reproducible y segura, que permite la cobertura de defectos severos en cualquier área de la extremidad superior inferior al codo, por lo cual actualmente y con nuestras condiciones de trabajo asistencial, es nuestra primera opción, con excelentes resultados y baja tasa de complicaciones.

\section{Dirección del autor}

Dra. María Camila Jaramillo Hurtado

Servicio de Cirugía Plástica

Hospital Universitario San Jorge de Pereira

Carrera 4 \# 24-88 Pereira, Risaralda (Colombia)

Correo electrónico: macaj2003@hotmail.com

\section{Bibliografía}

1. Jabaiti S, Ahmad M, Airyalat S. Reconstruction of upper extremity defects by random pedicle abdominal flaps: Is sti11 a valid option?. PRS Global open;.2020DOI: 10.1097/ GOX.0000000000002687

2. Naalla R, Chauhan Sh, Dave A, et al. Reconstruction of post-traumatic upper extremity soft tissue defects with pedicled flaps: An algorithmic approach to clinical decision making. Chinese Journal of Traumatology. 2018. https://doi.org/10.1016/j. cjtee.2018.04.005

3. Mitz V, Elbaz JS, Vilde F. Study of dermal elastic fibers during 
plastic surgery of the trunk . Ann Chir Plast. 1975;20(1):31-43.

4. Richter D, Stoff A. Abdominoplasty procedures. En: Plastic Surgery 3rd edithion. Vol II. Ed: Peter C. Neliga, Ed: Elsevier. 2013, Pp:530-558.

5. Herter F, Ninkovic M, Ninkovic M. Rational flap selection and timing for coverage of complex upper extremity trauma. JPRAS. 2007(60):760-768.

6. Rehim S, Kowalski E, Chung K. Enhancing aesthetic outcomes of soft tissue coverage of the hand. Plast. Reconstr. Surg. 2015;135:413-428.

7. Mohammad M, Ahmed M. Defining the indications of pedicled groin and abdominal flaps in hand reconstruction in the current microsurgery era. J Hand Surg Am. 2016.http://dx.doi. org/10.1016/j.jhsa.2016.06.006

8. Khandelwal Sh. An Abdominal Flap to Save the Right Forearm and the Hand, Following a High-voltage Electric Burn in a Child: A Case Report. J. Clin. Diagnostic Res. 2013, (7):1473-1475.

9. Monreal R, Gómez D, Osinaga G, et al. Reconstruction of the hand defects by pedicle abdominal thin skin flaps. JOJ Orthoped Ortho Surg. 2017. https://juniperpublishers.com/jojoos/pdf/JOJOOS.MS.ID.555555.

10. Delgado J. Experiencia clínica en reconstrucción de defectos de cobertura de la mano. Cir. plást. iberolatinoam. 2017(43);19-25.

11. Flügel A, Kehrer A, Heitmann C, et al. Coverage of soft tissue defects with free fascial flaps. Microsurgery. 2005;(25):47-53.

12. Urushidate S, Yotsuyanagi T, Yamauchi M. Modified thin abdominal wall flap (glove flap) for the treatment of acute burns to the hands and fingers. JPRAS. 2010;(63):693e-699.

13. McGregor IA, Jackson IT. The groin flap. Br J Plast Surg.
1972;25:3-16.

14. Li YY, Wang JL, Lu Y, et al. Resurfacing deep wound of upper extremities with pedicled groin flaps. Burns. 2000;(26):283-288.

15. Gousheh J, Arasteh E, Mafi P. Super-thin abdominal skin pedicle flap for the reconstruction of hypertrophic and contracted dorsal hand burn scars. Burns. 2008;(34):400-405.

16. Maruyama Y. Ohnishi K. Chung C. Vertical abdominal fasciocutaneous flaps in the reconstruction of chest Wall defects. Br.J.Plast.Surg. 1985. (38): 230-233.

17. Barillo D, Arabitag R, Cancio L. Distant pedicle flaps for soft tissue coverage of severely burned hands: an old idea revisited. Burns. 2001;(27):613-619.

18. Campillo R. Rodriguez JI. Cabezuelo E, et al. Mano eléctrica quemada: casuística de 5 años en el Hospital Universitario Rio Hortega de Valladolid, España. Cir. plást. iberolatinoam. 2017;(43):231-237.

19. Hunt JL, McManus WF, Haney W, et al. Vascular lesions in acute electrical injuries. $J$ Trauma. 1974;14:461-473.

20. Yamada $\mathbf{N}$, Uchinuma $\mathbf{U}$, Uchinuma E. The use of a thin abdominal flap in degloving finger injuries. Br.J.Plast.Surg. 2001;(54):434-438.

21. Silva S. Desnutrición en Colombia desde lo social, lo económico y lo político. Rev Soc Colomb Ped.2 016;15(2):7-19. 
